University of Nebraska - Lincoln

DigitalCommons@University of Nebraska - Lincoln

\title{
Comparison of the wing polyphenic response of pea aphids (Acyrthosiphon pisum) to crowding and predator cues
}

\author{
Swapna R. Purandare \\ swapna.purandare@huskers.unl.edu \\ Brigitte Tenhumberg \\ University of Nebraska - Lincoln, btenhumberg2@unl.edu \\ Jennifer A. Brisson \\ University of Nebraska - Lincoln, jennifer.brisson@rochester.edu
}

Follow this and additional works at: https://digitalcommons.unl.edu/bioscitenhumberg

Purandare, Swapna R.; Tenhumberg, Brigitte; and Brisson, Jennifer A., "Comparison of the wing polyphenic response of pea aphids (Acyrthosiphon pisum) to crowding and predator cues" (2014). Brigitte Tenhumberg Papers. 1.

https://digitalcommons.unl.edu/bioscitenhumberg/1

This Article is brought to you for free and open access by the Papers in the Biological Sciences at DigitalCommons@University of Nebraska - Lincoln. It has been accepted for inclusion in Brigitte Tenhumberg Papers by an authorized administrator of DigitalCommons@University of Nebraska - Lincoln. 


\title{
Comparison of the wing polyphenic response of pea aphids (Acyrthosiphon pisum) to crowding and predator cues
}

\author{
Swapna R. Purandare, ${ }^{1}$ Brigitte Tenhumberg, ${ }^{1,2}$ and Jennifer A. Brisson ${ }^{1}$ \\ 1. School of Biological Sciences, University of Nebraska-Lincoln, Lincoln, Nebraska, USA \\ 2. Department of Mathematics, University of Nebraska-Lincoln, Lincoln, Nebraska, USA \\ Corresponding author - Swapna R. Purandare, School of Biological Sciences, University of Nebraska-Lincoln, \\ Lincoln, NE 68588-0118, USA, email swapna.purandare@huskers.unl.edu
}

\section{Abstract}

1. Pea aphids (Acyrthosiphon pisum Harris; Hemiptera: Aphididae) exhibit transgenerational wing polyphenism, in which unwinged females produce genetically identical winged offspring in response to environmental cues such as overcrowding and predation risk that indicate poor habitat quality.

2. Laboratory experiments were carried out to explore the intensity of the wing polyphenic response of pea aphids exposed to cues from ladybird predators and crowding, and their response was compared with pea aphids that were not exposed to any cues (control).

3. The study used cues from two different ladybird species-Coccinella septempunctata L. (Coleoptera: Coccinellidae) and Hippodamia convergens Guérin-Méneville (Coleoptera: Coccinellidae) - to investigate whether the wing polyphenic response of pea aphids to predator cues can be generalized.

4. The intensity of the wing polyphenic response of pea aphids to crowding was found to be much stronger than their response to predator cues. There was no response to $H$. convergens cues and the response to $C$. septempunctata cues was mixed.

Keywords: Crowding, dispersal, polyphenism, predation risk, wing induction

\section{Introduction}

Polyphenism is an extreme form of phenotypic plasticity in which alternate, discrete phenotypes are produced from the same genotype as a response to environmental variation (Nijhout, 1999). The pea aphid (Acyrthosiphon pisum) exhibits a transgenerational wing polyphenism, in which unwinged asexual females produce genetically identical winged offspring. Winged morphs engage in long-range dispersal and thus can escape declining habitat quality, but long-range dispersal is risky because it mainly occurs passively through wind (Dieckmann et al., 1999; Compton, 2002), and consequently a large proportion of dispersers die before reaching a new host plant (Ward et al., 1998). Furthermore, the costs for producing winged morphs include an extended development time and reduced fecundity (Dixon, 1998).

Crowding conditions induce the production of winged offspring in aphids because host plant quality deteriorates when the number of feeding aphids is high (Sutherland, 1969a,b). Aphids also experience elevated mortality risk if the density of natural enemies and/or pathogens is high, and hence transgenerational wing polyphenism in aphids can be induced by the presence of parasitoids (Sloggett \& Weisser, 2002), pathogens (Hatano et al., 2012), and aphid predators (Weisser et al., 1999; Kunert \& Weisser, 2003). For wing induction via predation, it is sufficient for aphids to encounter cues associated with high predation risk such as predator tracks (Dixon \& Agarwala, 1999; Mondor et al., 2005).

Aphid predators are mobile and may leave an area soon after depositing cues. Thus, the presence of predatory cues may not predict poor habitat quality with the same certainty as crowding, in which case we would expect a weaker intensity of the wing polyphenic response. In order to understand the costs and benefits of dispersal, it is important to evaluate the intensity of wing polyphenism associated with different habitat quality indicators. We compared the intensity of the wing polyphenic response of pea aphids to crowding and cues of two different ladybird species, Coccinella septempunctata and Hippodamia convergens. Our results provide an insight into understanding the interactions between two fundamental ecological processes, predation and dispersal. 


\section{Materials and methods}

\section{Insect collection and rearing}

Predators. Adult C. septempunctata were collected from an alfalfa field in Lincoln, Nebraska, in July 2011, while adult $H$. convergens were purchased from commercial suppliers (Hirt's Gardens, Wadsworth, Ohio) in May 2011. Both coccinellid species were reared in chiffon-netted aluminum cages $(44 \times 51 \times 61 \mathrm{~cm})$ in growth chambers at approximately $25^{\circ} \mathrm{C}$ and LD 16:8 h on Vicia faba L. plants infested with pea aphids.

Aphids. Three pea aphid clones were used to increase the generalization of our results because different aphid clones vary in their sensitivity to environmental cues and in their wing polyphenic response (Sutherland, 1969a; Weisser \& Braendle, 2001). To prevent mixing of clones, all aphids were caged by enclosing the host plant $V$. faba using Plexiglass tubes $(21.5 \mathrm{~cm}$ high and $6.5 \mathrm{~cm}$ diameter) with a mesh on top. The aphids were maintained in the laboratory at 17 $\pm 1.5^{\circ} \mathrm{C}, \mathrm{RH} 35-45 \%$, and LD 16:8 $\mathrm{h}$.

\section{Experimental procedure}

The experiments were carried out in growth chambers at $17 \pm 1.5^{\circ} \mathrm{C}$, RH $35-45 \%$, and LD 16:8 h. Pea aphids were maintained on $V$. faba plants at low density (six individuals per plant) until they started reproducing. Aphids reared on the same plant were divided randomly between the treatments to avoid differences in the maternal environment that could influence their offspring phenotype. Pea aphids are viviparous, and therefore adult asexual females have embryos in their ovaries. Since the winged/unwinged morph determination in pea aphids is prenatal (Sutherland, 1969a,b), all experimental treatments were applied to adult asexual females within the first 3 days of the beginning of their reproductive period.

The experimental arena consisted of a plastic Petri plate $(60 \mathrm{~mm} \times 15 \mathrm{~mm}$, Fisher) with two Medicago arborea leaves inserted in $3 \mathrm{ml}$ of $2 \%$ bactoagar mixed with Miracle-Gro (The Scotts Miracle-Gro Company, Marysville, Ohio) (plate). Leaves, rather than plants, were used in order to restrict the predator cues to a small area, which increased the probability that aphids encountered the cues during the experiment. Adult unwinged asexual female pea aphids were divided randomly between the following treatments:

- Predator cues. One well-fed adult of either H. convergens or C. septempunctata was released in the experimental arena. The predators were allowed to search and deposit cues (eggs, feces, and tracks) at $22^{\circ} \mathrm{C}$ and $\mathrm{LD} 16: 8$ $\mathrm{h}$ under fluorescent light for $24 \mathrm{~h}$. As the response of aphids to ladybird tracks can depend on the predator sex (Ninkovic et al., 2013), we included both sexes in our experiments and randomly distributed them between the treatments. After removal of the predator, one adult, unwinged aphid female was placed in each plate.
- Crowding. Ten adult unwinged aphid females were placed in a small empty plastic Petri dish $(32.5 \mathrm{~mm} \times 15$ $\mathrm{mm}$ ) for $24 \mathrm{~h}$, and then each individual was transferred to its own plate. In our statistical analysis, we included only one randomly chosen aphid per Petri dish.

- Control. A single adult, unwinged aphid female was placed in a plate; predator cues were absent.

The response of aphids to predator tracks is known to decrease with the age of the tracks (Ninkovic et al., 2013). Therefore, female aphids were removed from all plates after $24 \mathrm{~h}$, the offspring produced during that duration were reared until they reached adulthood $(14 \pm$ 2 days), and the phenotype of the offspring after reaching maturity was recorded. We recorded the proportion of pea aphid females producing at least one winged offspring ("induced aphids") and the proportion of winged offspring produced by induced pea aphid females. The experiments were replicated for each of the three aphid clones (Hf-alf-07, seven replicates; Roc-1, six replicates; HF-74, four replicates).

All analyses were performed using R (v. 2.15.0; R Development Core Team, 2012). Backward model selection was performed and likelihood ratio tests were used to decide which model fitted the data best. A generalized linear mixed model (GLMM) with a binomial error distribution was used to analyze the proportion of induced aphids, treating clone and treatment as fixed effects and starting date as a random effect. The same statistical model was used to analyze the proportion of winged offspring produced by each induced aphid.

\section{Results}

Aphid clone had no significant effect on the proportion of aphids induced (Hf-alf-07, $P=0.17$; Roc- $1, P=0.33$; table S1 in supporting information) and the proportion of winged offspring produced by the induced aphids (Hfalf-07, $P=0.30$; Roc- $1, P=0.92$; table S2 in supporting information). Crowding produced a strong wing polyphenic response. In comparison to the control treatment (no cues), the proportion of induced aphids $(P=0.001$, fig. 1) and the proportion of winged offspring produced by induced aphids $(P=0.0001$, fig. 2$)$ were significantly higher than in the control. Exposure to C. septempunctata cues elicited a weak but significant response. Compared with the control, the proportion of induced aphids increased significantly $(P=0.003)$, but the proportion of winged offspring produced by induced aphids decreased $(P=0.03)$. By contrast, exposure to $H$. convergens cues had no effect on the proportion of induced aphids $(P=0.14)$ and winged offspring $(P=0.87)$.

\section{Discussion}

We found a strong wing polyphenic response of pea aphids to crowding (roughly twice as high as the control; fig. 1), 


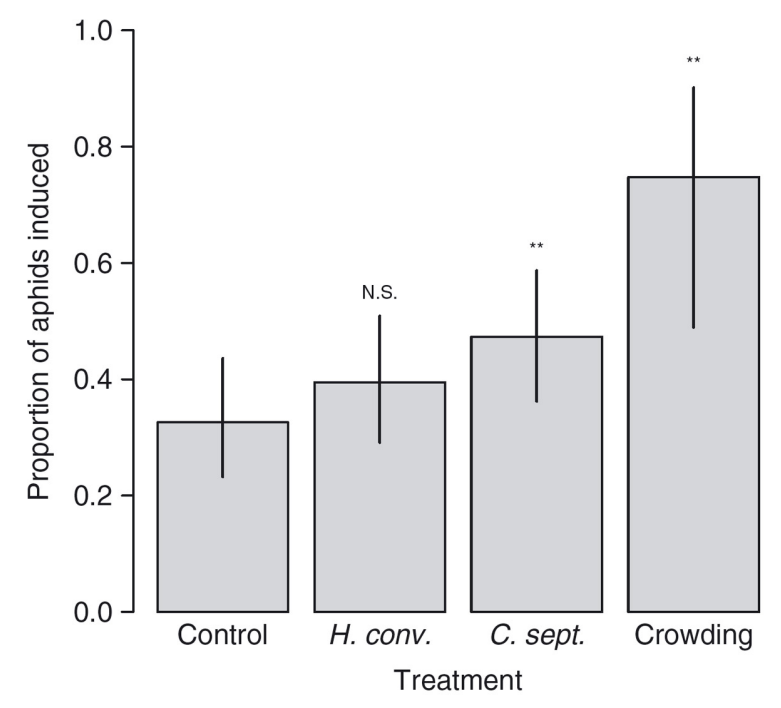

Figure 1. Proportion of induced pea aphids for each treatment. The bars indicate the mean values, and the lines show the $95 \%$ confidence interval. Control, no cues; $H$. conv., exposure to Hippodamia convergens cues; C. sept, exposure to Coccinella septempunctata cues; crowding, exposure to crowding. All comparisons are made with respect to the control.

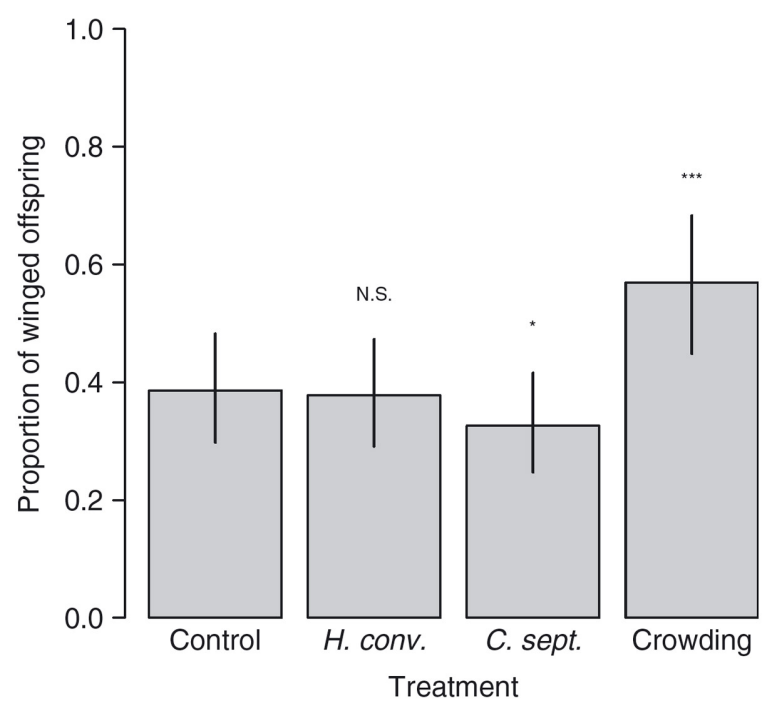

Figure 2. Proportion of winged offspring produced by induced pea aphids for each treatment. The bars indicate the means, and the lines show the 95\% confidence interval. Control, no cues; H. conv., exposure to Hippodamia convergens cues; C. sept, exposure to Coccinella septempunctata cues; crowding, exposure to crowding. All comparisons are made with respect to the control.

which is consistent with previous studies (Sutherland, $1969 a, b)$. We found no response of pea aphids to $H$. convergens cues and a mixed response to $C$. septempunctata cues. Even though the proportion of induced aphids $\left(P_{\text {induced }}\right)$ was significantly higher in aphids exposed to $C$. septempunctata cues, the proportion of winged offspring $\left(P_{\text {offspring }}\right)$ was lower than the control aphids, suggesting that the total dispersal response to predator cues is negligible $\left[P_{\text {induced }} P_{\text {offspring }}=12 \%\right.$ (Control), $13 \%(H$. convergens), and $14 \%$ (C. septempunctata)]. We suggest two potential reasons for the weak response to predator cues. First, the wing polyphenic response is transgenerational in pea aphids, and the delay between the time the females are induced and the offspring dispersal response is substantial. Thus, the predatory ladybird that induces the production of winged offspring in an aphid colony is unlikely to be present when the winged offspring mature (Minoretti \& Weisser, 2000). The evolution of delayed predator-induced dispersal is only adaptive under special circumstances. According to a model by Poethke et al. (2010), a substantial proportion (more than $80 \%$ ) of the population should disperse only if the predation risk is high $(\geq 0.8)$, predators revisit patches (return probability $\geq 0.8$ ), and predator-induced mortality increases after the first visit of a predator. These conditions may not apply to ladybirds foraging for aphids. Secondly, it is possible that our predator treatment did not provide a sufficient number of cues to induce a strong wing polyphenic response. In our predator treatment, we used isolated aphids to separate the effect of predator cues on wing induction from cues (such as tactile cues) associated with crowding (Sutherland, 1969a). Only a weak response by isolated pea aphids to predator tracks has been observed in a different aphid-coccinellid system (pea aphids-Adalia bipunctata; Dixon \& Agarwala, 1999).

Acknowledgments - We would like to thank two anonymous reviewers for their helpful comments, Emily Zahn for her help with aphid rearing and conducting the experiments, and Travis Hinkelman for the useful discussions. This work was supported by the University of Nebraska-Lincoln School of Biological Sciences Startup Funds and NIEHS award 4R00ES017367 (JAB) and University of Nebraska-Lincoln School of Biological Sciences Special Funds (SRP).

\section{References}

Compton, S. G. (2002) Sailing with the wind: Dispersal by small flying insects. Dispersal Ecology (ed. by J. M. Bullock, R. E. Kenward, and R. S. Hails), pp. 113-133. Blackwell Science Ltd., Oxford, UK.

Dieckmann, U., O'Hara, B., \& Weisser, W. W. (1999) The evolutionary ecology of dispersal. Trends in Ecology \& Evolution, 14, 88-90.

Dixon, A. F. G. (1998) Resource tracking in time. Aphid Ecology: An Optimization Approach (ed. by A. F. G. Dixon), pp. 128170. Chapman \& Hall, London, UK.

Dixon, A. F. G., \& Agarwala, B. K. (1999) Ladybird-induced life history changes in aphids. Proceedings of the Royal Society of London Series B: Biological Sciences, 266, 1549-1553.

Hatano, E., Baverstock, J., Kunert, G., Pell, J. K. \& Weisser, W. W. (2012) Entomopathogenic fungi stimulate transgenerational wing induction in pea aphids, Acyrthosiphon pisum (Hemiptera: Aphididae). Ecological Entomology, 37, 75-82.

Kunert, G., \& Weisser, W. W. (2003) The interplay between density and trait-mediate effects in predator-prey 
interactions a case study in aphid wing polymorphism. Oecologia, 135, 304-312.

Minoretti, N., \& Weisser, W. W. (2000) The impact of individual ladybirds (Coccinella septempunctata, Coleoptera: Coccinellidae) on individual aphid colonies. European Journal of Entomology, 97, 475-479.

Mondor, E. B., Rosenheim, J. A. \& Addicott, J. F. (2005) Predator induced transgenerational phenotypic plasticity in the cotton aphid. Oecologia, 142, 104-108.

Nijhout, H. F. (1999) Control mechanisms of polyphenic development. Bioscience, 49, 181-192.

Ninkovic, V., Feng, Y., Olsson, U., \& Pettersson, J. (2013) Ladybird footprints induce aphid avoidance behavior. Biological Control, 65, 63-71.

Poethke, H. J., Weisser, W. W. \& Hovestadt, T. (2010) Predator induced dispersal and the evolution of conditional dispersal in correlated environments. American Naturalist, 175, 577-586.

R Development Core Team. (2012) R: A Language and Environment for Statistical Computing. R Foundation for Statistical Computing, Vienna, Austria http://www.R-project.org [accessed on 26 December 2012].
Sloggett, J. J. \& Weisser, W. W. (2002) Parasitoids induce production of the dispersal morph of the pea aphid, Acyrthosiphon pisum. Oikos, 98, 323-333.

Sutherland, O. R. W. (1969a) The role of crowding in the production of winged forms by two strains of the pea aphid, Acyrthosiphon pisum. Journal of Insect Physiology, 15, 1385-1410.

Sutherland, O.R.W. (1969b) The role of the host plant in the production of winged forms by two strains of the pea aphid Acyrthosiphon pisum. Journal of Insect Physiology, 15, 2179-2201.

Ward, S. A., Leather, S. R., Pickup, J., \& Harrington, R. (1998) Mortality during dispersal and the cost of host-specificity in parasites: How many aphids find hosts? Journal of Animal Ecology, 67, 763-773.

Weisser, W. W. \& Braendle, C. (2001) Body colour and genetic variation in winged morph production in the pea aphid. Entomologia Experimentalis et Applicata, 99, 217-223.

Weisser, W. W., Braendle, C., \& Minoretti, N. (1999) Predatorinduced morphological shift in the pea aphid. Proceedings of the Royal Society B: Biological Sciences, 266, 1175-1181. 
Supplementary Table S1: Proportion of pea aphids induced. The predicted proportion of induced aphids for each of the treatment is depicted in Figure 1. $\mathrm{SE}=$ standard error .

\begin{tabular}{|l|l|l|l|}
\hline Fixed Effects & Estimate & SE & P Value \\
\hline Control and Clone HF-74 (Intercept) & -0.72 & 0.38 & 0.054 \\
\hline Predator Treatment-C7 & 0.66 & 0.21 & $0.0017^{* *}$ \\
\hline Predator Treatment-HC & 0.31 & 0.21 & 0.14 \\
\hline Crowding Treatment-CR & 1.81 & 0.56 & $0.001^{* *}$ \\
\hline Clone HF-alf-07 & -0.61 & 0.45 & 0.17 \\
\hline Clone Roc-1 & 0.4 & 0.44 & 0.33 \\
\hline
\end{tabular}


1 Supplementary Table S2: Proportion of winged offspring produced by induced pea

2 aphids. The predicted proportion of induced aphids for each of the treatment is

3 depicted in Figure 2. SE = standard error.

4

\begin{tabular}{|l|l|l|l|}
\hline Fixed Effects & Estimate & SE & P Value \\
\hline Control and Clone HF-74 (Intercept) & -0.55 & 0.31 & 0.0795 \\
\hline Predator Treatment-C7 & -0.26 & 0.12 & $0.03 *$ \\
\hline Predator Treatment-HC & -0.02 & 0.13 & 0.87 \\
\hline Crowding Treatment-CR & 0.78 & 0.19 & $4.97 \mathrm{e}-05$ *** \\
\hline Clone HF-alf-07 & 0.39 & 0.38 & 0.30 \\
\hline Clone Roc-1 & -0.04 & 0.37 & 0.92 \\
\hline
\end{tabular}

5

6 